\title{
O DESIGN COMO POTENCIALIZADOR PARA ALCANÇAR A INOVAÇÃO NO REAPROVEITAMENTO DE RESÍDUOS INDUSTRIAIS: TECNOLOGIA PARA AGREGAR VALOR NA PRODUÇÃO DE PISOS INTERTRAVADOS
}

\author{
Vanessa Cristine Silva \\ Mestre em Tecnologia do Ambiente Construído e Patrimônio Sustentável \\ Universidade Federal de Minas Gerais \\ vanessacristinesilva@gmail.com
}

Resumo: O presente trabalho apresenta uma análise sobre a importância do reaproveitamento de resíduos industriais na cadeia produtiva de pisos intertravados. Para compreensão deste estudo é apresentada uma metodologia baseada em revisão bibliográfica pertinentes ao tema e uma pesquisa de campo, baseada numa investigação realizada através de uma observação direta da cadeia produtiva numa indústria de pisos intertravados no município de Pedro Leopoldo em Minas Gerais. A interpretação dos resultados da pesquisa demonstra o potencial de inovação tecnológica no reaproveitamento de resíduos industriais como matéria-prima em pisos intertravados. É nesse sentido, que se fomenta o exercício da pesquisa multidisciplinar, visto que um número crescente de publicações tem abordado o tema resíduo industrial em diversos campos do conhecimento.

Palavras-chave: inovação, resíduos industriais, piso intertravado

\begin{abstract}
This work presents an analysis of the importance of recycling of industrial waste in the production chain of interlocked floors. For understanding of this study is presented a methodology based on literature review relevant to the theme and a field research, based on a research conducted through a direct observation of the productive chain in an industry of interlocked floors in the city of Pedro Leopoldo, Minas Gerais. The interpretation of the results of research demonstrates the potential of technological innovation in the recycling of industrial waste as a raw material in interlocked floors. It is in this direction, which encourages the exercise of multidisciplinary research, whereas a growing number of publications have addressed the industrial residue in several fields of knowledge.
\end{abstract}

Keywords: innovation, industrial waste, interlocked floor. 


\section{INTRODUÇÃO}

Todas as atividades industriais geram um impacto no meio ambiente. Neste caso, os impactos que acontecem nas várias fases do processo, desde o transporte, manuseio e preparação da matéria-prima, passando por sua transformação em produtos finais, até a destinação que se dá aos diversos resíduos que resultam dessas várias etapas de produção. A elevação de custos das matérias-primas e a escassez de recursos naturais têm estimulado a busca de alternativas mais sustentáveis para o reaproveitamento de resíduos. O conceito de desenvolvimento sustentável pressupõe na imposição de limites do consumo de recursos para a produção de bens, ou seja, os recursos naturais podem se esgotar e, no futuro a humanidade pagará o preço por isso.

Para tanto, a leitura desse cenário despertou uma reflexão sobre a possibilidade de potencializar a inovação tecnológica no reaproveitamento de resíduos industriais na produção de pisos intertravados, como objetivo geral desta pesquisa.

Nesse contexto, para a formulação da questão norteadora deste estudo "como o design pode contribuir para agregar valor aos resíduos industriais em pisos intertravados", parte-se do pressuposto que o reaproveitamento de resíduos representa melhoria de desempenho e competitividade no mercado, e contribui como valor agregado ao produto final, estabelecendo uma conexão entre a inovação tecnológica e a minimização da degradação ambiental.

O procedimento metodológico adotado na pesquisa utiliza uma abordagem qualitativa. Esse tipo de pesquisa procura viabilizar a formulação de cada etapa do trabalho a partir da revisão bibliográfica e desenvolver novos conhecimentos através dos dados coletados em campo. Este artigo foi desenvolvido em duas etapas: a primeira constitui uma revisão bibliográfica a partir de autores que reportam o tema abordado, que pretendeu elaborar um referencial teórico para fornecer fundamentos para a análise da investigação de campo coletada. A segunda etapa foi realizada uma observação direta durante uma visita no pátio industrial da empresa Uni-Stein no município de Pedro Leopoldo - Minas Gerais, onde foi possível inteirar-se de um sistema integrado computadorizado para a fabricação de pisos convencionais. A análise envolveu desde a etapa do processo produtivo, o recebimento da matériaprima na indústria até o produto ser disponibilizado para o consumidor final. Durante esta visita foi realizada uma entrevista semi-estrutura com aplicação de um questionário de forma livre, seguindo de um roteiro de questões abertas, que será explicado na investigação em campo.

\section{REFERENCIAL TEÓRICO}

É no universo da imaginação criativa que encontramos o papel do design e sua relação peculiar com o ser humano. Lidar com a complexidade do mundo atual é formar o conhecimento científico numa abordagem inter e multidisciplinar. Neste contexto o design representa o ator principal desta formação, ele é o simbólico, ou seja, é a essência da mente inovadora e o fator crucial de mudança econômica e cultural. Cabe ressaltar que é na observação que se encontra a descoberta da inovação, e foi no meio da inquietude da pesquisadora vivenciada no cenário de uma indústria, que surgiu o interesse em desenvolver esta pesquisa como contribuição do saber científico. Os temas deste artigo estão relacionados com o potencial de inovação 
no uso de resíduos industriais como matéria-prima alternativa em pisos intertravados e de subsidiar o papel do design nesse contexto.

\subsection{0 entrelaçamento indissolúvel: desgin e inovação}

A Inovação permeia todas as atividades, incluindo as mais tradicionais como a agricultura e as indústrias de bens de consumo e de capitais e serviço. Reportando a formulação da pergunta norteadora da pesquisa: "como o design pode contribuir para agregar valor aos resíduos industriais em pisos intertravados", a inovação é associada ao design, ambos representam a melhoria de desempenho e competitividade no mercado.

Em 1950 Joseph Shumpeter, relata na sua obra "Capitalism, Socialism and Democracy", que inovação é o fenômeno de geração de riquezas e oportunidades, através da ruptura do estado de equilíbrio da economia. A sua popular teoria, chamada de destruição criativa, é definida como a mudança incessante na estrutura do capitalismo, isto é, da substituição de velhos produtos e hábitos por novas aplicações para um produto já existentes. Desse modo, Schumpeter, argumenta que o empreendedor inovador é o propulsor do desenvolvimento econômico, pois, ao inovar, sua produção é imitada por outros capitalistas, gerando uma onda de capital ativa para a economia. (Schumpeter, 1934/1942, p. 66).

Freeman (1997) argumenta que a inovação, de um lado, envolve o reconhecimento de uma necessidade e, por outro, envolve um conhecimento técnico, incluindo novas informações científicas e tecnológicas. Pesquisa e desenvolvimento pode ser então, uma maneira de responder às tentativas de se vincular às possibilidades técnicas ao mercado.

Na obra de Kuhn, a ciência é dogmática, o seu desenvolvimento segue o paradigma do período. No entanto, essa mudança dos valores, teorias e métodos irão influenciar e servir de modelo para as revoluções científicas. As crises se manifestam a partir de controvérsias ao redor de metodologias, teorias, valores e conceitos no campo científico. Quando surgem novas concepções paradigmáticas, dá-se início a um período de transição. Nesse período há muito para ser feito, pois a ansiedade pelo novo é muito mais forte do que a tentativa de revigorar o velho paradigma (KUHN, 2003).

O ativismo em torno da sustentabilidade tem gerado reflexões interessantes sobre o papel do design. Segundo Manzini, as inovações sociais a partir de novas tecnologias surgidas, espontaneamente, dentro de determinados núcleos sociais, podem mudar o rumo de acontecimentos que tenderiam a conduzir o planeta a fins catastróficos. Este questionamento aponta sua inquietude na responsabilidade para com o meio ambiente. O passado do capitalismo modista deveria ser negligenciado e as questões ecológicas deveriam estar impregnadas no discurso e no trabalho dos designers (MANZINI, 2008, p.63).

Identificar o potencial de uso resíduos industriais, deve ser entendido como uma filosofia de gerenciamento, observando-se, igualmente, critérios técnicos, econômicos e ambientais associados à sua geração, manuseio, processamento, estocagem e destinação final.

Os critérios técnicos do processamento e da destinação final devem fundamentar-se na melhor tecnologia disponível e aplicável à rota selecionada. Já os 
critérios econômicos, conferem sustentabilidade ao sistema, e os ambientais previnem possíveis impactos que são nocivos à flora e fauna e à saúde humana, além de preservar os recursos naturais.

\subsection{Pavimentação intertravada}

Os maiores avanços tecnológicos ocorridos nas últimas décadas estão relacionados com a demanda de produtos ecologicamente corretos. Este fato se justifica na incorporação de técnicas sustentáveis para a construção civil. No Brasil, os pavimentos intertravados, conhecidos como "pavers", são aplicados atualmente em larga escala em todas as regiões do País pelo o seu aspecto estético que proporciona no ambiente construído e, como contribuição na redução do escoamento de águas devido ao seu sistema de intertravamento. A origem do pavimento intertravado é referida na Mesopotâmia há quase 5.000 anos A.C. e muito utilizado na Itália desde 2.000 A.C. Todavia, foi logo após a segunda guerra mundial que os pisos passaram a ser produzidos em grande escala, principalmente na Alemanha, tomando grande impulso na década de 70, quando chegaram ao Brasil. Hoje os países em desenvolvimento lideram o uso de intertravados em pavimentação como: Costa Rica, Colômbia, Nicarágua e com grande uso nas estradas no estado de São Paulo, Brasil. Atualmente os pisos intertravados de concreto são utilizados em larga escala para pavimentações dentre as quais se destacam: passeios públicos, estradas, terminais de portos e aeroportos, ruas e avenidas, pontos de ônibus, parques e jardins, estradas, estacionamentos e pátios com manobras, pisos em áreas industriais, galpões, depósito de mercadoria, faixas demarcatórias e de sinalização, pisos rurais como currais e bebedouros, postos de gasolina, áreas de exposições e feiras, e ainda na possibilidade de assentamento em rampas íngremes (FERNANDES, 2013).

A norma NBR 9781/2013, define pavimento intertravado como pavimento flexível cuja estrutura é composta por uma camada de base (ou base e sub-base), seguida por camada de revestimento constituída por peças de concreto justapostas a uma camada de assentamento e cujas juntas entre as peças, são preenchidas por material de rejuntamento. O intertravamento do sistema é proporcionado pela contenção (Concrete Institute Pavement (ICP), 2013).

\subsection{A produção de pavimentos intertravados com o uso de materiais alternativos.}

O objetivo desta subseção é identificar a existência da formação de uma cadeia ambientalmente sustentável através de resíduos advindos da indústria. De fato, a utilização de resíduos em novos produtos representa uma melhoria na vida das pessoas. Sob este prisma, as pesquisas envolvendo as indústrias de pavimentos intertravados têm-se propagado por todo o mundo, com o intuito de trazer benefícios para o meio ambiente através da reciclagem.

i. Pisos intertravados com copolímero de etileno-acetato de vinila - EVA

Em seu experimento, Lyra (2007), estudou a possibilidade de substituir em até $50 \%$ do volume de areia na composição de pisos intertravados pelo resíduo de EVA (Copolímero de Etileno-Acetato de Vinila) moído e no pó de pedra com o resíduo EVA em pó. A contribuição de sua pesquisa indicou para a diminuição do consumo de areia e a reciclagem e destinação dos resíduos de EVA. Os resultados apontaram que o uso 
do EVA moído apresenta maior eficiência no uso do resíduo, pois permitiu uma maior quantidade na mistura em torno de $27 \%$, ao contrário do pó de EVA, que apresentou baixa resistência e menor aproveitamento do resíduo.

Desse modo, a viabilidade técnica com a incorporação do EVA moído foi comprovada, desde que sua aplicação seja para pavimentação de calçadas e passeios públicos.

\section{ii. Pisos intertravados com resíduos de construção civil e fibras de aço}

No programa experimental de sua pesquisa, Santos (2014), avaliou a influência dos resíduos de construção com fibras de aço para a produção de pisos intertravados. Os ensaios de caracterização dos materiais, conforme prescreve a norma NBR 9781:2013, comprovam a viabilidade da produção dos pisos intertravados com esses resíduos considerando os resultados satisfatórios de resistência à compressão e à abrasão. Este trabalho apresenta uma contribuição científica de forma ambientalmente adequada proporcionando benefícios para a sociedade de ordem social e econômica.

\section{iii. Pisos intertravados com resíduos de recauchutagem de pneus}

O trabalho de Fioriti, Ino e Kasaki (2007), destaca a importância da reciclagem do resíduo de recauchutagem que gera uma grande quantidade, sendo necessária a sua redução como contribuição ao meio ambiente. Os procedimentos avaliados foram os ensaios à compressão, absorção e resistência ao impacto que apresentaram uma baixa resistência à compressão; entretanto os pisos demonstraram uma elevada capacidade de absorção de energia. Portanto o resultado final do experimento indicou a possibilidade da utilização dos resíduos de borracha para pavimentação intertravada apenas para as sobrecargas leves.

\section{iv. Pisos intertravados com resíduos de retífica de cerâmica}

Esta proposta realizada por Carvalho (2013) teve o objetivo de utilizar o resíduo de retífica de placas cerâmicas de revestimento de peças pré-moldadas de concreto para uso em pavimento intertravado, substituindo a dosagem parcial da areia e do cimento nas porcentagens de $5 \%$ a $30 \%$ na massa. Conforme relatado pelo autor, os resultados atenderam aos requisitos da norma brasileira podendo-se afirmar que sobre, o ponto de vista técnico, a incorporação de resíduos de revestimentos cerâmicos é uma boa alternativa para a produção de pisos intertravados.

\section{v. Pisos intertravados com resíduos de mineração}

A reciclagem de rejeitos de minérios na produção de piso intertravado contribui para a sustentabilidade no piso que foi patenteado em 2010 com o nome de pavieco, inspirado no peixe pacu, espécie da bacia do rio São Francisco e instalado no estacionamento e passeio do supermercado Verdemar, localizado em Nova Lima Minas Gerais.O pavieco é produzido por rejeitos de mineração sedimentados nos cursos d'água em barragens e rios da região de Macacos, São Sebastião de Águas Claras, Minas Gerais. A Bacia Viva, empresa idealizadora do projeto, já forneceu o piso para 3,7 mil metros quadrados na rua Monte Vista, no Bairro Jardim Canadá e, também, o Instituo Kairós em Macacos. 


\section{vi. A produção de pisos intertravados com escória de aciaria}

Este projeto realizado em 2010, pela indústria de aço ArcelorMittal na unidade em Juiz de Fora/MG, comprovou que a utilização da escória de aciaria na fabricação de pisos intertravados sextavados foi economicamente viável, ambientalmente correta e está inserida no contexto da sustentabilidade oferecendo vantagens em relação aos disponíveis no mercado. Foram fabricadas 1.500 unidades, numa área de $131 \mathrm{~m}^{2}$ no entorno das instalações industriais na usina, onde se realizou a avaliação do comportamento dos pisos frente aos fatores físicos (como a compressão pelo tráfego de veículos pesados no local), fatores climáticos (como chuva e temperatura) e ambientais (solubilização e lixiviação). O piso intertravado sextavado oferece benefícios para projetos e usuários: é $25 \%$ mais barato que outros pisos tradicionais, evita consumo de recursos naturais não renováveis (areia e brita) e tem maior permeabilidade, flexibilidade, resistência à compressão e característica antiderrapante. Portanto, a fabricação dos pisos intertravados é mais uma alternativa para as empresas do ramo siderúrgico transformar seus resíduos, gerados nos processos produtivos, em co-produtos.

No quadro 01, apresenta-se uma comparação das vantagens e desvantagens, e custo estimado da adição dos resíduos industriais para a produção de pisos intertravados.

Quadro 01 - Quadro comparativo da adição de resíduos industriais na produção de piso intertravado

(continua)

\begin{tabular}{|c|c|c|c|c|}
\hline $\begin{array}{l}\text { Tipos de Materiais } \\
\text { empregados em } \\
\text { pavimentação }\end{array}$ & Vantagens & Desvantagens & $\begin{array}{l}\text { Quantidade } \\
\left(\mathrm{m}^{2}\right)\end{array}$ & $\begin{array}{l}\text { Valor } \\
(\mathbf{R} \$) \\
\text { Estimado }\end{array}$ \\
\hline Concreto (fck=25 Mpa) & $\begin{array}{l}\text { Possui alta durabilidade; } \\
\text { superfície regular e } \\
\text { antiderrapante, } \\
\text { proporcionando conforto } \\
\text { ao usuário }\end{array}$ & $\begin{array}{l}\text { Custo alto, aquecimento } \\
\text { no ambiente }\end{array}$ & 1 & $\mathrm{R} \$ 44,00$ \\
\hline Asfalto & $\begin{array}{l}\text { Apresenta rapidez na sua } \\
\text { execução }\end{array}$ & $\begin{array}{l}\text { Manutenção } \\
\text { problemática e } \\
\text { aquecimento do } \\
\text { ambiente }\end{array}$ & 1 & $\mathrm{R} \$ 34,44$ \\
\hline $\begin{array}{l}\text { Piso intertravado } \\
\text { convencional }\end{array}$ & $\begin{array}{l}\text { Conforto térmico, } \\
\text { resistência } 25 \text { a } 50 \mathrm{Mpa}, \\
\text { facilidade de manutenção }\end{array}$ & $\begin{array}{l}\text { Utiliza como matéria- } \\
\text { prima a exploração do } \\
\text { recurso natural } \\
\text { (areia,brita) }\end{array}$ & 1 & $\mathrm{R} \$ 28,00$ \\
\hline $\begin{array}{l}\text { Etileno-acetato de vinila - } \\
\text { EVA }\end{array}$ & $\begin{array}{l}\text { Produção sustentável } \\
\text { redução do consumo da } \\
\text { areia em } 50 \%\end{array}$ & $\begin{array}{l}\text { Sua aplicação fica } \\
\text { limitada apenas para } \\
\text { calçadas e passeios. } \\
\text { Baixa resistência }\end{array}$ & 1 & $R \$ 24,00$ \\
\hline Resíduos de Construção civil & $\begin{array}{l}\text { Produção sustentável } \\
\text { redução de brita e areia } \\
\text { Resistência a compressão e } \\
\text { abrasão satisfatória }\end{array}$ & Apenas uso Tráfego leve & 1 & $\mathrm{R} \$ 20,00$ \\
\hline $\begin{array}{l}\text { Resíduos de Recauchutagem } \\
\text { de pneus }\end{array}$ & $\begin{array}{l}\text { Produção sustentável } \\
\text { Apresentou uma elevada } \\
\text { capacidade de absorção de } \\
\text { energia }\end{array}$ & $\begin{array}{l}\text { Utilizada apenas em } \\
\text { pavimentação com } \\
\text { sobrecargas leves } \\
\text { Baixa resistência a } \\
\text { compressão }\end{array}$ & 1 & $\mathrm{R} \$ 24,00$ \\
\hline
\end{tabular}




\begin{tabular}{|c|c|c|c|c|}
\hline $\begin{array}{l}\text { Resíduos de Retífica de } \\
\text { cerâmica }\end{array}$ & $\begin{array}{l}\text { Produção sustentável } \\
\text { substituição parcial do } \\
\text { cimento e da areia nas } \\
\text { porcentagnes de } 5 \text { a } 30 \%\end{array}$ & Apenas uso Tráfego leve & 1 & $R \$ 20,00$ \\
\hline $\begin{array}{l}\text { Resíduos de rejeito de } \\
\text { mineração }\end{array}$ & $\begin{array}{l}\text { Produção sustentável } \\
\text { substituição parcial do } \\
\text { cimento e da areia } \\
\text { Apresenta maior } \\
\text { resistência }\end{array}$ & Apenas uso Tráfego leve & 1 & $\mathrm{R} \$ 20,00$ \\
\hline $\begin{array}{l}\text { Resíduos de siderúrgica - } \\
\text { escória de aciaria }\end{array}$ & $\begin{array}{l}\text { Produção sustentável } \\
\text { substituição parcial do } \\
\text { cimento e da areia } \\
25 \% \text { mais baratos que o } \\
\text { convencional }\end{array}$ & $\begin{array}{l}\text { Necessidade de } \\
\text { beneficiamento do } \\
\text { resíduo a remoção } \\
\text { completa do óxido de } \\
\text { ferro }\end{array}$ & 1 & $\mathrm{R} \$ 20,00$ \\
\hline
\end{tabular}

Fonte: Elaborado pela autora, 2016.

\section{INVESTIGAÇÃO EM CAMPO}

A realização da visita à Indústria Uni-Stein visou levantar informações sobre o processo de fabricação de pisos intertravados convencionais. Para este estudo, utilizou-se a técnica da observação em campo incluindo registros fotográficos e a seleção de informações através de uma entrevista semi-estrutura. Para compor o processo industrial, foram observadas as seguintes unidades: recebimento de material, silos de britagem, misturador, prensa vibratória, estufa e laboratórios.

A equipe de produção é composta por três colaboradores com o acompanhamento de dois técnicos de produção em dois turnos. Todo o processo industrial é automatizado com equipamento proveniente da Espanha, garantindo o maior controle da qualidade através de uma gestão integrada.

Todos os seus fornecedores estão posicionados até um raio de $75 \mathrm{~km}$ da indústria, podendo-se adquirir a areia, brita e cimento (Holcin e Cimento Lins) com custos baixos das tarifas de frete de transporte, além de ser mais seguro e rápido. No que tange ao meio ambiente, menor redução de gases poluentes e preservação das estradas na redução de veículos terrestres. Desse modo, o modelo de desenvolvimento sustentável acima citado apresenta uma nova forma de encontrar uma vantagem competitiva de mercado e alcançar valor agregado à organização. Para as comunidades do entorno do trecho, o ganho é maior na diminuição de emissões de $\mathrm{CO}_{2}$ no ambiente.

O controle do recebimento é feito da seguinte forma: a matéria-prima é pesada e encaminhada para as baias de depósito próximo à unidade industrial acompanhado de nota fiscal discriminando a data e a quantidade do produto. Primeiramente, é realizada a análise visual constatando a homogeneidade do material.

Observa-se que, na fabricação de pisos intertravados, o procedimento é realizado através de um equipamento automático denominado central dosadora e misturadora automática. Trata-se de um sistema integrado, composto por quatro silos, uma esteira e um misturador, que trabalham com sensores eletrônicos de forma a distribuir as quantidades de material necessárias conforme o traço do piso especificado. Cada silo possui uma correia individual para garantir uma dosagem adequada dos materiais proporcionando maior controle na qualidade dos produtos. Quando a quantidade está completa, todo o agregado é descarregado para um misturador através de um esteira transportadora. Neste equipamento, adicionam-se os aditivos, a água e os pigmentos gerando uma mistura homogênea que, em seguida, 
será depositada em moldes para ser vibro-prensadas. Verifica-se, então, que este processo propicia uma redução de mão de obra significativa, além de evitar desperdícios de materiais contribuindo para o alcance da produção sustentável da empresa. Para controlar todo o processo de fabricação dos pisos intertravados, os equipamentos estão ligados a um centro de controle. A resposta programada, através de um painel eletrônico, irá atuar nos dispositivos eletrônicos inseridos na planta industrial. As entradas nestes dispositos vão determinar a composição dos traços de insumos dos produtos.
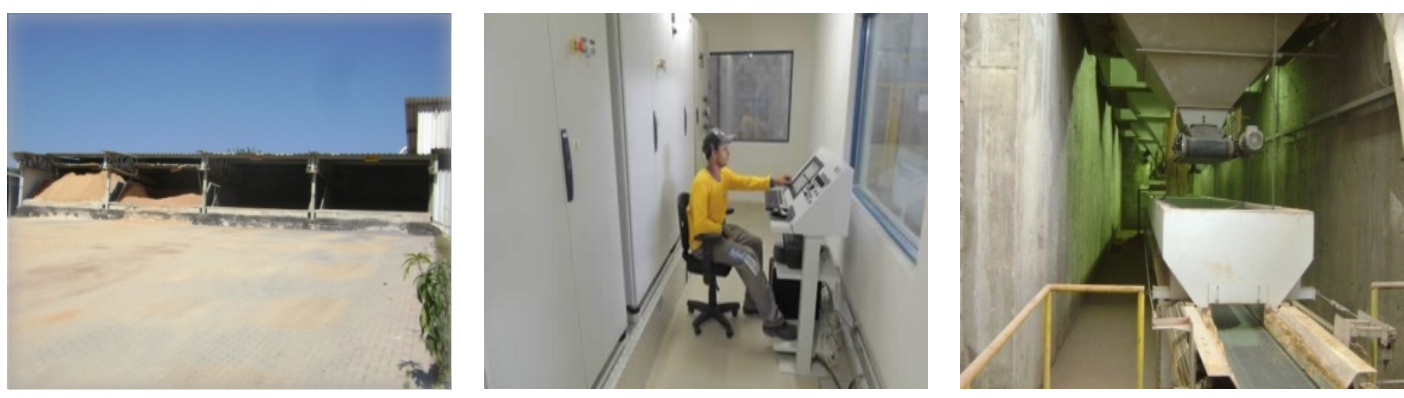

Figura 1: Seleção e dosagens de materiais,

“Elaborado pela autora, com base na pesquisa realizada, 2015.

Após a dosagem e a mistura dos materiais, é realizada a etapa de vibroprensagem dos pisos. O concreto do misturador segue para a alimentação da máquina de prensa hidráulica, onde ocorre a vibração a alta compressão hidráulica.

Segundo relato da Uni-stein, este equipamento garante alta resistência à compressão, flexão, torção, atrito e insensibilidade ideal contra choques.
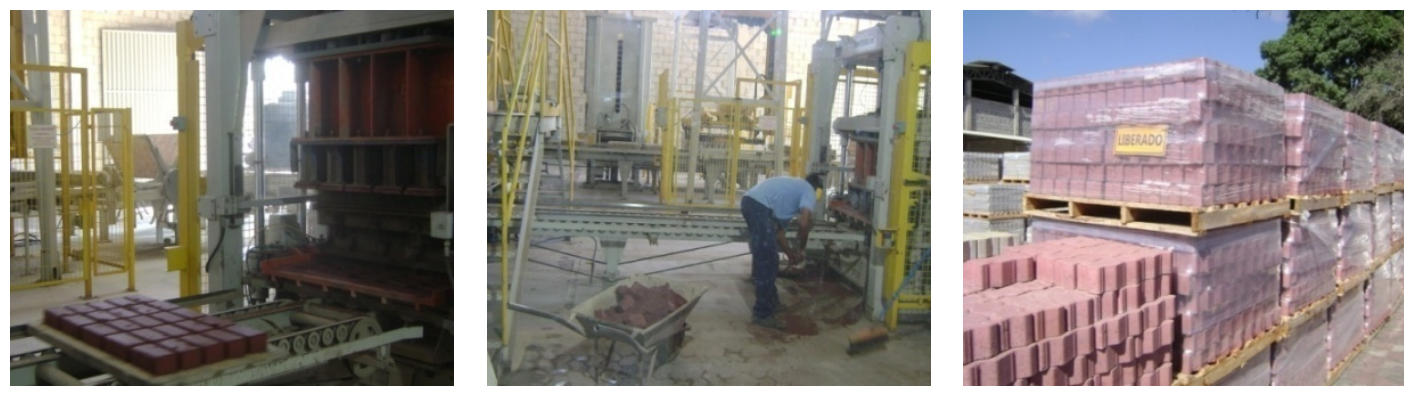

Figura 2: Prensagem, separação e paletização dos pisos,

“Elaborado pela autora, com base na pesquisa realizada, 2015.

A reciclagem na fábrica é identificada e caracterizada pela economia no processo de produção. Os restos de pavimento resultantes da prensa durante a modelação são coletados manualmente e recolocados no misturador. É importante registrar que as peças defeituosas podem retornar ao processo produtivo, como também os pisos não curados e que quebram devido a falhas de manuseio.

Após a moldagem, as peças seguem para as estufas de cura térmica com temperatura e umidade controladas, para garantir a maior hidratação do cimento e resistência do produto. Observa-se, dentro do galpão industrial, a utilização de um sistema automático de carregamento e descarregamento das prateleiras fixas que transportam bandejas com os pisos recém prensados para a estufa de cura e, também, a retirada das bandejas com produtos curados para a próxima etapa. Verifica-se que, após o tempo de cura de aproximadamente 24 a 36 horas, as peças são encaminhadas 
através de uma empilhadeira para a etapa de paletização do produto e a aplicação de um filme plástico transparente em toda a extensão do palete, para servir de embalagem e proteção das peças.

No seu laboratório, a Uni-stein realiza ensaios tais como: granulometria, absorção e resistência à compressão conforme determina a norma da ABNT/NBR 9781/2013 - Peças de concreto para pavimentação - especificação, garantindo o controle da qualidade das peças fabricadas.

$\mathrm{Na}$ Figura 3, observa-se o conjunto de peneiras utilizadas no ensaio para a determinação da composição granulométrica dos agregados. Para o ensaio de resistência à compressão, os pisos são colocados na prensa e alinhados de forma que o seu centro de gravidade fique alinhado ao centro de carga dos cilindros de aço superior e inferior, na qual recebe uma aplicação de carga de compressão de uma velocidade de $0,5 \mathrm{MPa} / \mathrm{s}$.

Para realizar o ensaio de absorção de água é inserido corpos de prova saturados conforme a norma ABNT/NBR 9781/2013 em uma estufa com temperatura a $(110 \pm 5){ }^{\circ} \mathrm{C}$, mantendo está condição por 24 horas.
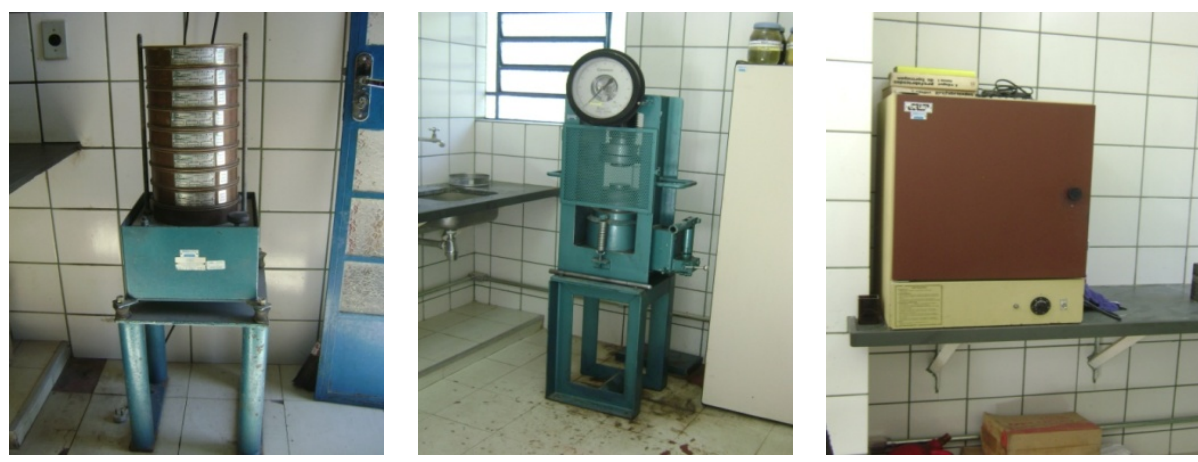

Figura 3: Ensaio de granulometria, compressão e absorção dos pisos,

“Elaborado pela autora, com base na pesquisa realizada, 2015.

Durante esta investigação, foi elaborado um roteiro de perguntas abordando considerações importantes sobre a produção e controle de qualidade dos pisos intertravados. Esta entrevista foi realizada de forma presencial, na sala do gerente de produção durante a visita à fábrica Uni-Stein, localizada, e teve a duração de cinquenta minutos. Antes da entrevista, explicou-se ao entrevistado a finalidade da visita, o objetivo da pesquisa e a importância de sua colaboração dentro do assunto abordado.

Pode-se considerar que esta entrevista foi dividida em duas partes. A primeira parte destinou-se a obtenção de informações relativas à capacidade de produção de pisos intertravados da Uni-Stein, o tipo da matéria-prima usado, a dosagem das misturas e custos de material do produto final. Para a segunda parte da entrevista, foram levantadas questões sobre o uso de insumo alternativo. Para tanto, este roteiro foi elaborado para que o entrevistado se sentisse à vontade para desenvolver suas próprias ideias e relatar suas experiências de forma descontraída.

\subsection{Análise e discussão dos resultados}

O primeiro ponto de análise utilizou a entrevista presencial para entender os fatos estudados que não puderam ser observados pela autora durante a visita. Buscou- 
se conhecer a capacidade de produção da indústria e o processo de separação das matérias-primas para a mistura do produto final.

Questão 01: qual a produção mensal de pisos intertravados? Uni-Stein: “ $a$ planta industrial da Uni-Stein tem capacidade de produzir $60.000 \mathrm{~m}^{2}$ de pisos intertravados por mês. Entretanto, hoje, produz aproximadamente $25.000 \mathrm{~m}^{2}$ dos seguintes modelos de pisos intertravados: tipo prisma, 16 faces, sextavado, pisograma, raquete e meio-fio com espessuras padronizadas nas medidas de $60,0 \mathrm{~mm}, 80,0 \mathrm{~mm}$ e $100,0 \mathrm{~mm}$ e comercializados para a construção civil em diversas cidades de Minas Gerais e também em outros estados."

Questão 02: quais as matérias-primas usadas? Uni-Stein: "na fábrica são armazenados cerca de 100 toneladas de agregados: areia natural, areia artificial, pó de pedra, brita zero, além do cimento e do aditivo plastificante."

Questão 03: como é feita a dosagem dos traços? Uni-Stein: "o fator primordial para a eficiência do processo produtivo no sistema de dosagem é um estudo detalhado da curva granulométrica dos materiais, isto porque o traço depende das características físicas e da qualidade dos agregados."

Questão 04: qual o tempo de cura na estufa? Uni-Stein: "é sabido que a cura total do concreto é de 28 dias no ambiente, entretanto hoje a Uni-Stein possui um sistema de cura por câmaras de aquecimento de temperatura em média de 70 , proporcionando um resultado satisfatório na qualidade do produto. Em um dia, podese obter uma resistência da peça entre 35\% a 70\%, e, logo após 7 dias, a peça adquire 95\% de resistência."

Questão 05: qual o custo unitário de materiais por $\mathrm{m}^{2}$ ? Uni-Stein: "este procedimento é realizado através do peso da peça por metro quadrado e o traço de sua composição; é necessário primeiramente calcular a quantidade de cimento em gramas. Para o custo unitário de material da empresa obteve-se a seguinte composição de custo relacionada às espessuras do piso intertravado: espessura de 60,0 $\mathrm{mm}$ o custo seria de $R \$ 10,50$ (dez reais e cinqüenta centavos), para espessura de $80,0 \mathrm{~mm}$ obtevese o custo de $R \$ 14,00$ (quatorze reais) e, finalmente para a espessura de 100,0 mm $R \$$ 17,50 (dezessete reais e cinqüenta centavos) para o custo unitário do material."

Questão 06: as dimensões desses produtos podem variar conforme especificação do cliente? Uni-Stein: "uma empresa interessada em fabricar produtos de qualidade deve atender às reais necessidades de seus clientes. A escolha do produto é do cliente, mas a análise dimensional deverá cumprir os requisitos da norma NBR 9781 de 2013 - Peças de concreto para pavimentação - Especificação e métodos de ensaio, cujo conteúdo é de responsabilidade de um comitê de estudo, na qual faz parte o gerente de produção José Goulart da Uni-Stein. A NBR 9781 cita que os pisos intertravados podem ser produzidos em diversos formatos conforme as medidas de cada fabricante. Entretanto, a variação das dimensões e suas respectivas tolerâncias deverão atender às referidas medidas de comprimento, largura e espessura considerando os planos perpendiculares e paralelos às arestas das peças."

Questão 07: saberia dizer se a permeabilidade do piso intertravado convencional é semelhante ao piso intertravado de resíduo industrial? Uni-Stein: "o que difere a absorção de água é a porosidade da peça, quanto menor o tempo em que a água é absorvida na superfície do piso maior será a quantidade de vazios e, portanto, tanto o piso convencional quanto o de material reciclado apresenta-se com uma baixa 
resistência. Não saberia distinguir a permeabilidade de uma peça convencional de outra produzida com resíduo de minério ou a escória siderúrgica.

Questão 08: poderia dizer se o uso de resíduo em substituição à matéria-prima convencional possibilita redução de custo de produção (custo homem $\mathrm{x}$ hora) e (custo de materiais)? Uni-Stein: "em relação ao custo de materiais haveria uma redução no custo; no fator homem / hora, ficaria o mesmo valor."

O primeiro ponto de análise utilizou a entrevista presencial para entender os fatos estudados que não puderam ser observados pela autora durante a visita. Buscouse conhecer a capacidade de produção da indústria e o processo de separação das matérias-primas para a mistura do produto final.

A Uni-Stein utilizou o resíduo industrial escória siderúrgica em um experimento em 2004, com adição de cimento CPIV na produção de artefatos para a construção. Foi comprovado que a escória de aciaria atrasa a cura, mas o interessante é que sua resistência é maior que o piso convencional. De fato, a escória siderúrgica é um grande insumo, mas existe a problemática de sua estabilidade, visto que hoje a tecnologia é limitada para o seu tratamento. Os resultados indicaram que a entrevistada apresentou atributos que poderiam ser alcançados nos objetivos da pesquisa.

\section{CONCLUSÃO}

Os resultados obtidos na análise de campo desta pesquisa em conjunto com as informações contempladas na revisão bibliográfica indicam a potencialidade de inovação tecnológica no uso dos resíduos industriais como matéria-prima alternativa na produção de pisos intertravados; e também como uma contribuição positiva para o meio ambiente, com a minimização dos recursos naturais não renováveis: a areia e a brita.

O exposto nesta pesquisa apontou que os resíduos industriais agregam valor ao produto em termos de resistência, redução de custos de materiais de produção, além de contribuir para aumentar a competitividade do produto, com a possibilidade de gerar rentabilidade no mercado. Nesse sentido, é imprescindível difundir suas vantagens técnicas para a comunidade científica.

Este artigo visou a levantar novas experiências sobre outras possibilidades de obtenção de produtos por meio de resíduos industriais, e também fomentou a reflexão sobre a produção de pisos intertravados de forma sustentável.

\section{REFERÊNCIAS}

ARCELORMITTAL: Disponível em:<http://www.arcelormittal.com>. Acesso em: 30 jun. 2014.

ASSOCIAÇÃO BRASILEIRA DE NORMAS TÉCNICAS. NBR 9.781: Peças de concreto para pavimentação, especificação e métodos de ensaio. 2013. 27p.

CARVALHO, Eduardo Viviani de. Utilização do resíduo da retífica de cerâmica de revestimento na produção de concreto para pavimento intertravado. 2013. $161 \mathrm{p}$. Dissertação (Mestrado em Tecnologia) - Faculdade de Tecnologia, Universidade Estadual de Campinas, Limeira, 2013. 
FERNANDES, I. D. Blocos \& pavers - Produção e controle de qualidade. 4a ed. São Paulo: Treino Assessoria e Treinamentos Empresariais, 2013. 200 p. ISBN: 978-8562290-03-9

FREEMAN, Christopher. The Economic of Industrial Innovation. 1997. Editora Pinter, 470 páginas.

FIORITI, C. F.; INO, A.; KASAKI, J. L., Avaliação de blocos de concreto para pavimentação intertravada com adição de resíduos de borracha provenientes da recauchutagem de pneus. Associação Nacional de Tecnologia do Ambiente Construído, Porto Alegre. v. 7, no 4, p.43-54, Out/Dez. 2007. ISS 1678-8621.

HAMMEL, G., The Future of Management. Boston: Harvard business School Press, 2007 HBS (Harvard Business School), Implementando a Inovação. Rio de Janeiro: Elsevier, 2007.

INTERLOCKING CONCRETE PAVEMENT INSTITUTE (ICPI), Tech Spec. no 14, 2013. Concrete paving units for roof decks. Uxbridge, Canada, 2013, p.12. Tech Spec. $n$ o 16, 2014. Achieving Leed credits with segmental concrete pavement. Uxbridge, Canada, 2014, p. 20.

KUHN, Thomas. A estrutura das revoluções científicas. Tradução de B. Boeira e N. Boeira. 3a ed. São Paulo: Perspectiva, 2003.

. T."Prophet of Innovation” (profeta da inovação), 2007.

LYRA, Mário Limeira de. Blocos intertravados de concreto com resíduos de copolímero de acetato de vinila - EVA - para pavimentação de calçadas e passeios públicos. 2007. 118 p. Dissertação (Mestrado em engenharia urbana) - Escola de engenharia, Universidade Federal da Paraíba, João Pessoa, 2007.

MANZINI, Ezio; VEZZOLI, Carlo. O desenvolvimento de produtos sustentáveis: os requisitos ambientais dos produtos industriais. Tradução de Astrid de Carvalho. São Paulo: Editora da Universidade de São Paulo. EDUSP. 2002.

SANTOS, Vânia Regina Ferreira dos. Análise do desempenho de pisos táteis, intertravados produzidos com agregados de resíduos de construção civil - RCC e fibras de aço. 2014. 117 p. Dissertação (Mestrado em Tecnologia) - Faculdade de Tecnologia, Universidade Estadual de Campinas, Limeira, 2014.

SCHUMPETER, J. (1950). Capitalism, Socialism and Democracy. 3rd edn. New York: Harper and Row. 